\title{
O QUE É HERMENÊUTICA PARA PAUL RICOEUR? ${ }^{1}$
}

\author{
Thiago Luiz de Sousa ${ }^{2}$ \\ Universidade Federal de Minas Gerais (UFMG) \\ https://orcid.org/0000-0001-6188-1954 \\ E-mail: thiago-luiz-sousa@hotmail.com
}

\section{RESUMO:}

O conceito possivelmente que resume melhor o pensamento filosófico de Paul Ricoeur (1913-2005) é hermenêutica. No entanto, diferentemente do que acontece com o maior nome da tradição hermenêutica, o filósofo alemão HansGeorg Gadamer (1900-2002), a definição do termo hermenêutica em Ricoeur não se dá de maneira unívoca. Sendo assim, faz-se necessário trilhar um caminho em algumas de suas obras para compreender os sentidos de um dos conceitos mais fundamentais para tal filósofo francês. Pretende-se, assim, com o presente artigo analisar a definição tripla de hermenêutica, como interpretação, método e reflexão, que é apresentada em $A$ Crítica e a Convicção, com uma metodologia análoga ao do próprio Ricoeur, que está presente em A Memória, a História e o Esquecimento e em O Percurso do Reconhecimento. A partir disso, busca-se compreender tais sentidos analisados, percorrendo o caminho sugerido em Escritos e conferências 2: hermenêutica, onde se vê mapeados os sentidos que hermenêutica possuiu ao longo da obra ricoeuriana, e destacar o aspecto original desta noção, que se dá através da hermenêutica pensada por meio de uma filosofia reflexiva.

PALAVRAS-CHAVE: Paul Ricoeur; Hermenêutica; Filosofia Reflexiva.

\section{WHAT IS HERMENEUTICS FOR PAUL RICOEUR?}

\begin{abstract}
:
The concept that possibly better sums up the philosophical thought of Paul Ricoeur (1913-2005) is hermeneutics. However, differently to what happens with the most important name of the hermeneutic tradition, the German philosopher Hans-Georg Gadamer (1900-2002), the definition of the concept hermeneutics in Ricoeur does not show up in an univocal manner. Therefore, it is necessary to find a way in some of his works in order to understand the meanings of one of the most fundamental concepts to the French philosopher. We intend, thus, with the present paper, to analyse the triple definition of hermeneutics as interpretation, method and reflection, which are presented in $A$ Crítica e a Conviçã̃o, with a methodology analogous to that of Ricoeur himself, which is present in $A$ Memória, a História e o Esquecimento and in O Percurso do Reconhecimento. From that, we aim to understand these analysed meanings, in the way suggested by Escritos e conferências 2: hermenêtica, where we see as mapped the meanings that hermeneutics had along the work of Ricoeur, and to emphasize the original aspect of this notion, which is given through the hermeneutics considered under a reflexive philosophy.
\end{abstract}

KEYWORDS: Paul Ricoeur; Hermeneutics; Reflexive Philosophy.

\footnotetext{
${ }^{1}$ Este artigo é uma revisão da dissertação de mestrado $O$ estatuto de uma Hermenêutica Filosófica e seu enriquecimento para a Hermenêutica Bíblica em Paul Ricoeur e surgiu a partir dos comentários de Cláudio Reichert do Nascimento, a quem o dedico. ${ }_{2}^{2}$ Doutorando em Filosofia na Universidade Federal de Minas Gerais (UFMG), Belo Horizonte - MG, Brasil.
}

SOUSA, Thiago Luiz de. O que é hermenêutica para Paul Ricoeur?. Griot : Revista de Filosofia, Amargosa - BA, v.20, n.2, p.17-29, junho, 2020. 
Sem sombra de dúvidas, os grandes nomes da hermenêutica filosófica contemporânea são Hans-Georg Gadamer (1900-2002) e Paul Ricoeur (1913-2005). Porém, como aponta Jean Grondin em Paul Ricoeur, por mais que o termo "hermenêutica" seja o que melhor represente tanto este autor alemão, quanto este autor francês, eles chegam nisto de maneiras bem diferentes (GRONDIN, 2015, p. 14).Sendo assim, por mais que se diga que Gadamer e Ricoeur pertencem a uma mesma tradição filosófica, a hermenêutica contemporânea, não se pode dizer que realizar um diálogo entre tais autores seja algo simples, uma vez que, nos escritos de Gadamer, não se encontram referências a Ricoeur e, nos de Ricoeur, encontra-se uma leitura bem própria do pensamento gadameriano. Por isso, Roberto Roque Lauxen afirma que falar de "hermenêutica"em Paul Ricoeur não é o mesmo do que falar de "hermenêutica"em Gadamer (LAUXEN, 2012, p. 127-128).

Segundo Lauxen, isto é percebido claramente na relação que o termo "hermenêutica" tem para com a obra destes autores. No caso de Gadamer, podemos encontrar em Verdade e Método uma definição de "hermenêutica" que perpassa toda sua obra. No entanto, no caso de Ricoeur, o termo "hermenêutica" recebe definições diferentes e é enriquecido ao longo de sua obra (LAUXEN, 2012, p. 131). Sendo assim, enquanto em Gadamer há uma obra magna onde é apresentada a definição de hermenêutica, em Ricoeur tal definição se dá através de um caminho feito ao longo de suas obras e resumido em um dos seus escritos autobiográficos, $A$ Crítica e a Convicção.

Como afirma Gadamer em Verdade e Método, hermenêutica é "[...] uma disciplina do perguntar e do investigar, que garante a verdade" (GADAMER, 1997, p. 709), isto é, aquela verdade que o método cientifico não consegue alcançar, a hermenêutica, como um instrumento, por meio de uma fusão de horizontes, é capaz de revelar. Neste sentido, hermenêutica seria uma espécie de método dos métodos. Porém, para Ricoeur, tal definição seria apenas um dos significados que a hermenêutica possui, pois assim ele afirma em $A$ Crítica e a Conviç̧ão:

\begin{abstract}
Não penso que exista entre a hermenêutica e a epistemologia uma diferença de duas metodologias, dois projetos de inteligibilidade; as duas perspectivas cruzam-se sem cessar, interferindo constantemente e, em primeiro lugar, porque o termo "hermenêutica" subsume pelo menos três coisas: métodos precisos que comportam regras rigorosas - é o caso da filologia e da exegese dos grandes textos clássicos, como a jurisprudência; em seguida, uma reflexão sobre a própria natureza do próprio compreender, as suas condições e seu funcionamento; finalmente, um eixo mais ambicioso, uma espécie de "filosofia" que se apresenta como outra via da inteligibilidade, e que pretende compreender as condutas cientificas melhor do que elas próprias conseguiram, acantonando-os nos limites de uma espécie de "metodologismo". É um pouco a posição adoptada por Gadamer, em relação à qual me distanciei (RICOEUR, 1995, p. 105).
\end{abstract}

É esta definição plurívoca que o presente artigo pretende esclarecer.

Em Vivo até a morte Ricoeur afirma: "É aqui como em outros casos a tarefa mínima da reflexão filosófica: analisar, clarificar" (RICOEUR, 2012, p. 8). Tanto a análise, quanto a clarificação estão presentes em todas as obras filosóficas, porém tais tarefas encontram um curioso auxílio nos textos tardios de Ricoeur, os dicionários. Por exemplo, em $A$ memória, a história, o esquecimento, o filósofo francês cita um dicionário para apresentar os dilemas do 
perdão com a extensão que este conceito pode ter por meio da ideia de dom (RICOEUR, 2007, p. 465-512). Já em Percurso do reconhecimento os dicionários são o ponto inicial de toda discussão decorrente. Entretanto, como o próprio Ricoeur afirma em uma entrevista, este instrumento possui limites:

\begin{abstract}
Provavelmente porque o dicionário não exprime ainda as revoluções metodológicas que tiveram lugar na linguística. Trata-se, muito simplesmente, da distinção entre duas formas de tratar uma palavra. Podemos perguntar o que ela significa na língua, ou procurar ainda saber o que são os objetos de que ela fala. Os nossos dicionários misturam as duas coisas. Falam das coisas nomeadas e também falam do lugar das palavras no sistema lexical de uma língua. Os nossos dicionários são uma espécie de compromisso entre, por um lado, uma verdadeira semântica das palavras, isto é, a ordenação de uma palavra em relação a todas as outras, sem se ocuparem das coisas em si e, por outro lado, a descrição das coisas correspondentes (RICOEUR, 1976, p. 3).
\end{abstract}

Sendo assim, os dicionários não substituem uma análise pormenorizada das coisas. Porém, eles são bons guias de ordenação e descrição das coisas. Em Percurso do reconhecimento, Ricoeur dá um excelente exemplo de como o dicionário pode ser utilizado por um filósofo. Em tal obra, este recurso não aparece como auxílio para resolver um dilema, como em A Memória, a História, o Esquecimento, mas como apresentação de um conceito problemático, a saber, o conceito de reconhecimento. Desta forma, o filósofo francês, em um primeiro momento, recorre aos dicionários, para, depois de tal esclarecimento, iniciar uma discussão através de grandes obras filosóficas. Sua justificativa para esta estratégia metodológica é de que este conceito nunca foi trabalhado de maneira central e, por consequência, esclarecido por nenhum grande autor.

Deve existir uma razão para que nenhuma obra de boa reputação filosófica tenha sido publicada sob o título $O$ reconhecimento. A razão disso seria que estaríamos lidando com um falso verdadeiro conceito que oferece ao autor em busca de novidade a armadilha de um verdadeiro falso tema? E, no entanto, a palavra é recorrente em minhas leituras, ora aparecendo como um diabo inoportuno, ora sendo bem acolhida, até mesmo esperada nos lugares certos. Em que lugares? [...] Aqui se oferece o socorro dos dicionários (RICOEUR, 2006, p. 13).

Ora, se o conceito de reconhecimento é recorrente em suas leituras filosóficas, cabe ao filósofo saber se está lidando com um conceito ou com um pseudo-conceito, isto é, com um termo que aparenta ter um significado mais relevante para obra do que de fato tem. Assim, o lexicógrafo pode apresentar tanto os significados mais comuns, quanto um pouco dos significados mais técnicos sobre os termos, para se ter uma base conceitual para uma análise perante as obras filosóficas. Este modelo de análise é muito comum em escritos filosóficos, o de elucidação dos sentidos que determinado conceito apresentou perante a história da filosofia, a novidade de Ricoeur se dá no reconhecimento da importância que a linguagem coloquial tem perante tal tarefa. Para isto, ele utiliza o Grand Robert, o dicionário francês mais famoso e popular, com a intenção de identificar os sentidos do cotidiano, e a rigorosidade do Littré, o dicionário francês que apresenta os sentidos mais técnicos dos termos e como se desenvolveu ao longo da história, desde o passado até o presente (RICOEUR, 2006, p. 15). Se tal estratégia foi utilizada por Ricoeur para analisar o conceito "reconhecimento", o presente artigo fará o mesmo acerca do conceito "hermenêutica". 
O dicionário Aurélio é aquele que se pode encontrar em português a intenção de um dicionário voltado tanto para praticidade, quanto para utilidade, trazendo os vocábulos mais frequentes na língua portuguesa, em território nacional, entre os anos de 1900 a 2000, como indicado no prefácio à sua $5^{\mathrm{a}}$ edição (FERREIRA, 2010, p. XI). Esta intenção já se encontra desde sua $1^{\text {a }}$ edição, em que o lexicógrafo procura citar o uso dos verbetes, principalmente nos autores modernos (FERREIRA, 2010, p. XIV). Já o dicionário Houaiss é aquele que concentra o maior número de informações possível acerca dos verbetes. Desta forma, neste segundo dicionário, encontra-se a datação das entradas e o significado delas para diferentes áreas. Neste sentido, o dicionário Houaiss pode ser utilizado da mesma forma do Littré, e o Aurélio da mesma forma que o Grand Robert. Dito isso, pode ser traçado o seguinte caminho de análise: primeiramente, traça-se os significados usuais do termo "hermenêutica" através do dicionário Aurélio, uma vez que ele se destaca neste quesito e, depois, apresenta-se os sentidos mais técnicos do termo, utilizando o dicionário Houaiss, para, assim, conceituar "hermenêutica" e verificar a presença de tais sentidos ao longo da obra ricoeuriana.

Três definições de hermenêutica são encontradas no dicionário Aurélio, a saber, (a) interpretação do sentido das palavras; (b) interpretação dos textos sagrados; (c) arte de interpretar leis (FERREIRA, 2010, p. 1082). Destas definições, encontram-se no dicionário exemplos das duas últimas. $O$ que vemos, aqui, ressaltado por Aurélio é que, usualmente, na língua portuguesa o termo "hermenêutica" é utilizado como um sentido geral de interpretação, ou em um sentido instrumental, seja este para se referir a interpretação comum, como na primeira definição, ou seja este para interpretar textos sagrados ou leis, como na segunda definição, ou como uma arte, isto é, uma técnica, como apresenta a terceira definição. Já no dicionário Houaiss, encontram-se quatro definições de hermenêutica, a saber, (a) ciência, técnica que tem por objeto a interpretação de textos religiosos, ou filosóficos; (b) interpretação dos textos, dos sentidos das palavras; (c) teoria, ciência voltada à interpretação dos signos e do seu valor simbólico; (d) conjunto de regras e princípios usados na interpretação do texto legal (HOUAISS, VILLAR, 2009, p. 1014). Neste segundo dicionário, há algo complementar às definições apresentadas pelo Aurélio, pois hermenêutica não é vista apenas como interpretação em um sentido instrumental, mas também é vista como ciência/teoria. Assim, observa-se as definições fornecidas pelo Aurélio, pelo Houaiss e pelo Ricoeur de $A$ Crítica e A Convicção da seguinte maneira:

Quadro 1: Definições de hermenêutica

\begin{tabular}{|l|l|l|}
\hline \multicolumn{1}{|c|}{ AURÉLIO } & \multicolumn{1}{|c|}{ HOUAISS } & \multicolumn{1}{c|}{ PAUL RICOEUR } \\
\hline $\begin{array}{l}\text { (a) } \\
\begin{array}{l}\text { Interpretação } \\
\text { do sentido das } \\
\text { palavras. }\end{array}\end{array}$ & $\begin{array}{l}\text { (a) Ciência, técnica } \\
\text { que tem por objeto a } \\
\text { interpretação de } \\
\text { textos religiosos, ou } \\
\text { filosóficos. }\end{array}$ & $\begin{array}{l}\text { (a) Métodos precisos que comportam regras } \\
\text { rigorosas - é o caso da filologia e da exegese dos } \\
\text { grandes textos clássicos, como a jurisprudência. }\end{array}$ \\
\hline $\begin{array}{l}\text { Ib) } \\
\text { dosterpretação } \\
\text { sagradoxtos. }\end{array}$ & $\begin{array}{l}\text { (b) Interpretação dos } \\
\text { textos, dos sentidos } \\
\text { das palavras. }\end{array}$ & $\begin{array}{l}\text { (b) Uma reflexão sobre a própria natureza do } \\
\text { próprio compreender, as suas condições e seu } \\
\text { funcionamento. }\end{array}$ \\
\hline $\begin{array}{l}\text { (c) Arte de } \\
\text { interpretar leis. }\end{array}$ & $\begin{array}{l}\text { (c) Teoria, ciência } \\
\text { voltada à } \\
\text { interpretação dos } \\
\text { signos e do seu valor }\end{array}$ & $\begin{array}{l}\text { (c) Um eixo mais ambicioso, uma espécie de } \\
\text { “filosofia" que se apresenta como outra via da } \\
\text { inteligibilidade, e que pretende compreender as } \\
\text { condutas cientificas melhor do que elas próprias }\end{array}$ \\
\hline
\end{tabular}

SOUSA, Thiago Luiz de. O que é hermenêutica para Paul Ricoeur?. Griot : Revista de Filosofia, Amargosa - BA, v.20, n.2, p.17-29, junho, 2020. 


\begin{tabular}{|l|l|l|}
\hline & simbólico. & $\begin{array}{l}\text { conseguiram, acantonando-os nos limites de } \\
\text { uma espécie de "metodologismo". }\end{array}$ \\
\hline & $\begin{array}{l}\text { (d) Conjunto de } \\
\text { regras e princípios } \\
\text { usados na } \\
\text { interpretação do } \\
\text { texto legal. }\end{array}$ & \\
\hline
\end{tabular}

Quando se confrontam as definições dos dicionários com aquelas sugeridas por Paul Ricoeur, percebe-se que as definições (b) "Interpretação dos textos sagrados" e (c) "Arte de interpretar leis" do Aurélio e todas as definições do Houaiss se enquadram na definição (a) "Métodos precisos que comportam regras rigorosas - é o caso da filologia e da exegese dos grandes textos clássicos, como a jurisprudência" de Ricoeur, onde o que é destacado é hermenêutica como técnica. Esta primeira definição se situa na média distância entre a definição (a) "Interpretação do sentido das palavras" do Aurélio, em que hermenêutica é vista simplesmente como alguma interpretação, e (c) "Um eixo mais ambicioso, uma espécie de 'filosofia' que se apresenta como outra via da inteligibilidade, e que pretende compreender as condutas cientificas melhor do que elas próprias conseguiram, acantonando-os nos limites de uma espécie de 'metodologismo"' de Ricoeur, em que ela é vista como um metodologismo, isto é, assim como a Filosofia da Linguagem é o horizonte das filosofias da linguagem, Hermenêutica seria o horizonte das hermenêuticas. Por fim, dentre as definições sugeridas por Ricoeur, há uma que não se encontra nos dicionários citados, a saber, (b) "Uma reflexão sobre a própria natureza do próprio compreender, as suas condições e seu funcionamento". Sendo assim, hermenêutica é, segundo Ricoeur, interpretação, método, como nos dicionários, e, além disso, reflexão, no sentido de um pensamento acerca do próprio pensamento.

\section{IV}

Em Escritos e conferências 2: hermenêutica, Paul Ricoeur descreve como o problema hermenêutico surgiu em sua obra filosófica, ele afirma que " [...] o problema da interpretação só me veio aos poucos, sempre por ocasião de uma problemática particular e limitada" (RICOEUR, 2011, p. 15). Percebe-se que o problema hermenêutico, pelo menos inicialmente, não é o alvo central da obra ricoeuriana, diferentemente do que acontece com Gadamer. Ou seja, por mais que posteriormente o filósofo francês leve em conta a definição de que a hermenêutica é uma reflexão sobre o próprio compreender e, sendo assim, uma propedêutica para toda investigação filosófica, nos seus primeiros escritos ele considera a hermenêutica apenas como uma alternativa interpretativa, isto é, uma outra interpretação possível para análise. Sendo assim, a hermenêutica é vista apenas como um instrumento nos primeiros escritos do filósofo francês, como um método que poderia ajudá-lo na reflexão filosófica perante seus problemas delimitados. Um exemplo desta hermenêutica, segundo o próprio Ricoeur, pode ser encontrado na obra $A$ simbólica do mal.

A questão que move $A$ simbólica do mal é "[c]omo fazer a transição entre a possibilidade do mal humano e a sua realidade, entre a falibilidade e a falta?" (RICOEUR, 2017, p. 19). A partir disso, Ricoeur estabelece o seguinte objetivo: "Tentaremos captar essa passagem [entre a possibilidade do mal humano e sua realidade] em ato, no momento em que se efetua, 'repetindo' em nós mesmos a confissão que dela é feita na consciência religiosa" (RICOEUR, 2017, p. 19). Para alcançar isso, segundo Jean Grondin, Ricoeur escuta a "[...] confissão da consciência, que se expressa nos grandes símbolos e mitos que narram o surgimento do mal" (GRONDIN, 2015, 
p. 49). Assim, a questão hermenêutica surge na obra de Ricoeur no momento em que ele tem de buscar nos mitos respostas para sua problemática filosófica. Como cita Grondin: "A hermenêutica, aquisição da 'modernidade', é um dos modos pelos quais esta modernidade se supera a si mesma, quanto ao esquecimento do sagrado" (RICOEUR apud GRONDIN, 2015, p. $55)$.

Do ponto de vista pessoal de Ricoeur, este ponto foi alcançado por conta de sua dupla cultura, tanto grega, quanto cristã. Ele próprio relata isso:

[...] certamente foi por causa da minha dupla cultura, bíblica e grega, que me sentia obrigado a incorporar à filosofia reflexiva vinda de Descartes e Kant a interpretação dos símbolos da mácula, do pecado, da culpabilidade, em que via a primeira camada simbólica da consciência do mal, em seguida a interpretação dos grandes mitos da queda: mitos cosmogônicos, órfico, trágico, adâmico. Podia assim falar de reflexão concreta, por não poder dar à própria interpretação desses símbolos e mitos o estatuto teórico designado pelo termo hermenêutica (RICOEUR, 2011, p. 18-19).

O problema hermenêutico aparece em $A$ simbólica do Mal a partir do desafio que o mal traz para reflexão. De um lado, o filósofo francês vê na linguagem de sua dupla cultura um lugar privilegiado para trabalhar sua problemática:

[...] as literaturas hebraica e helênica testemunham uma invenção linguística que assinala as erupções existenciais dessa consciência de culpa; é ao recuperar as motivações dessas invenções linguísticas que repetimos a passagem da mancha ao pecado e à culpabilidade: dessa forma, as palavras hebraicas e gregas que exprimem a falta têm uma espécie de sabedoria própria que a que explicitar e tomar como guia no labirinto da experiência viva; por conseguinte, nós não somos, de modo algum, reenviados para o inefável quando tentamos explorar as profundezas dos mitos do mal; uma vez mais, é numa linguagem que desembocamos (RICOEUR, 2017, p. 25).

Por outro lado, ele vê o quanto isso compõe um desafio para o tempo presente: "O momento histórico da filosofia do símbolo é o do esquecimento e da restauração. Esquecimento das hierofanias, dos sinais do sagrado, da perda do próprio homem enquanto pertencente ao sagrado" (RICOEUR, 2017, p. 367). Com isso, a hermenêutica é vista, em um primeiro momento por Ricoeur, como uma filosofia do símbolo, isto é, um método que a filosofia deve buscar para recuperar o sentido do sagrado em tempos de crise (primeira definição de hermenêutica presente na obra filosófica de Ricoeur).

Em uma entrevista, Paul Ricoeur aponta que a origem deste momento críticos e dá em "[...] um vasto processo histórico de distanciação das nossas raízes culturais" (RICOEUR, 1976, p. 1). Além disso, ele esclarece o que chama de raízes: “Quando eu penso em 'raízes', eu penso na nossa dupla ou tripla herança grega e judaico-cristã" (RICOEUR, 1976, p. 5). A hermenêutica seria, assim, uma aposta no poder simbólico, uma aposta de que é possível se apropriar do sentido do simbólico, que nossa modernidade se esqueceu. Hermenêutica seria, antes de qualquer coisa, um esforço custoso. $O$ próprio Ricoeur alerta tal esforço: "O esforço a fazer será extremamente custoso; não se trata mais de uma repetição, mas verdadeiramente de reinvenção. É o que chamo de hermenêutica" (RICOEUR, 1976, p. 5).

Diante disso, observar-se dois pontos: Paul Ricoeur não vê a crise da modernidade como uma espécie de "doença"; no entanto, esta crise deve ser superada. Em A simbólica do Mal, Ricoeur aponta tal crise como decorrência da própria modernidade: "Este esquecimento [o das nossas raízes], sabemo-lo, é a contrapartida da grandiosa tarefa que é alimentar os homens, satisfazer as necessidades dominando a natureza mediante uma técnica planetária" (RICOEUR, 2017, p. 367). Em A crise da consciência histórica e a Europa, Ricoeur reafirma o fato não 
acidental desta crise e aponta outro fator que também contribuiu para o surgimento dela, o cristianismo:

[...] o cristianismo, diferentemente do Islã, sempre se compôs com seu adversário racionalista e interiorizou a crítica em autocritica. Em certo sentido, a crise não é um acidente contingente, muito menos uma doença moderna: ela é constitutiva da consciência europeia. A heterogeneidade das tradições fundadoras e a discordância entre convicções e critica me levaram a pronunciar a palavra fragilidade (RICOEUR, 1994, p. 89).

É justamente a palavra fragilidade que assinala a necessidade de superar tal crise, pois, como o próprio Paul Ricoeur afirma, "[...] passa-se facilmente da fragilidade à patologia" (RICOEUR, 1994, p. 89). Deve-se tomar cuidado para que esta crise não venha desembocar em uma crise política, em que uma sociedade não se recorda de seu passado sofrido - o exemplo dado por Paul Ricoeur é o da ex-Iugoslávia, em que a sociedade apenas se lembra das glórias e se esquece da humilhação sofrida (RICOEUR, 1994, p. 89). Cremos que a tentativa que ocorre, no cenário nacional, ao enaltecer os lados positivos da ditadura militar brasileira também ilustra muito bem o perigo desta crise se tornar uma patologia. Dois níveis devem ser destacados em relação ao perigo que esta crise traz: o nível institucional e o nível reflexivo.

Segundo Paul Ricoeur, o destino da filosofia não deve ser confundido com o destino do ensino da filosofia (RICOEUR, 1976, p. 1), isto é, sempre teremos filósofos. No entanto, talvez, estes filósofos não estejam presentes na academia. Neste sentido, o filósofo francês vê um perigo institucional, que surge em decorrência da crise da nossa modernidade, o não espaço desta matéria nas universidades.

Efetivamente, a filosofia está assaz ameaçada na sua existência institucional devido à sua inutilidade em relação às ciências e pelo facto de que as outras formas do saber não lhe exigem mais nada. Diria que os filósofos, em lugar de acusar uns aos outros, deviam acusar-se de terem falado para si mesmos em vez de se terem ocupado em escutar as ciências (RICOEUR, 1976, p. 7-8).

Um dos filósofos que melhor analisou a questão da crise em nossa sociedade é Nietzsche, apelidando este tema como "niilismo" (RICOEUR, 1976, p. 1). Na verdade, Nietzsche mostra o quanto tal crise pode ser devastadora e é a partir disso que Ricoeur define o que é niilismo: “Chamamos 'niilismo' à convicção de que a herança está esgotada, de que o seu poder simbólico se esgotou" (RICOEUR, 1976, p. 5). No entanto, logo em seguida, a esta definição, o filósofo francês declara sua posição: "Sou daqueles que pensam que a tarefa da filosofia é de a reatualizar, e que nada jamais se perde" (RICOEUR, 1976, p. 5). Ora, esta posição adotada por Paul Ricoeur propõe, através da análise do simbólico, uma filosofia enriquecida, uma filosofia que não é alheia às raízes do passado. Desta maneira, o capítulo final de $A$ simbólica do Mal tenta responder a seguinte pergunta: será que uma filosofia que tem esta postura é possível? Ricoeur afirma:

É uma questão difícil, na medida em que se trata de avançar entre dois perigos: por um lado, é impossível justamente justapor simplesmente a reflexão e a confissão; já não é, de facto, possível interromper o discurso filosófico, à maneira de Platão, através das narrativas fantásticas e dizer: aqui termina o discurso, ali começa o mito; Lachelier tem razão: a filosofia deve compreender tudo, mesmo a religião; a filosofia não pode parar a meio do caminho; no começo, ela fez o juramento de coerência; deve manter até o fim sua promessa. Mas também já não é possível obter uma transcrição filosófica direta do simbolismo religioso do mal, sob pena de regressar a uma interpretação de caráter 
alegórico dos símbolos e dos mitos; dissemo-lo bastantes vezes: o símbolo não esconde nenhum ensinamento oculto que bastaria desmascarar e que tornaria as imagens inúteis. Entre estes dois impasses vamos explorar uma terceira via: a via de uma interpretação criadora de sentido, fiel ao impulso, à doação de sentido do símbolo e, simultaneamente, fiel ao juramento de compreensão do filósofo. É esta via, que requer paciência e rigor da nossa parte, que é indicada pelo aforismo proposto no início desta conclusão: “O símbolo dá que pensar" (RICOEUR, 2017, p. 365-366).

O símbolo traz um desafio para filosofia, ou melhor, nas palavras de Ricoeur, o símbolo dá o que pensar. Como o filósofo francês apresenta, diante do símbolo não se pode parar a reflexão como Platão, pois abrir-se-ia mão da pretensão da filosofia de compreender tudo; não se pode também interpretar os símbolos como simples alegorias, pois isto seria inútil. Sendo assim, a terceira via possível, a via da hermenêutica, seria uma aposta diversa à do niilismo, uma aposta de que nos símbolos se pode compreender algo que está obtuso em nossa modernidade, o elo entre o ser humano e o sagrado. Paul Ricoeur, com isso, não quer desmitologizar o mito, mas quer usufruir das riquezas que o mito pode oferecer.

Assim, se a modernidade trouxe instrumentos que, consequentemente, podem levar o ser humano ao esquecimento de suas raízes, ao esquecimento do seu elo com o sagrado, a mesma modernidade apresenta instrumentos que podem levar o ser humano a um novo descobrimento, a uma nova compreensão de suas raízes. $O$ apontamento da hermenêutica em $A$ simbólica do mal, de uma hermenêutica simbólica, nada mais é do que o reconhecimento de que se deve buscar aquilo que o símbolo tem a oferecer. Se, por conta de nossa modernidade, não se consegue mais alcançar a experiência que o mito explicita, pode-se "repeti-lo" (RICOEUR, 2017, p. 23), isto é, deve-se refletir sobre aquilo que o símbolo dá. Por isso, a expressão "o símbolo dá o que pensar" é a melhor representante desta hermenêutica: "o símbolo dá; mas aquilo que ele dá, é algo a pensar, algo sobre qual se pense" (RICOEUR, 2017, p. 366).

Neste sentido, a hermenêutica aparece na obra de Ricoeur como um desejo de "[...] dar resposta a uma certa situação da cultura moderna" (RICOEUR, 2017, p. 366). Esta situação, a partir de outros escritos do próprio autor, denomina-se crise. Duas considerações acerca da questão hermenêutica podem ser traçadas após esta breve reflexão:

Primeiro, se a modernidade está passando por uma crise cultural, em que seu maior sintoma é o esquecimento de suas raízes, a filosofia deve ser enriquecida por outras áreas do conhecimento, pois, caso contrário, não sobreviverá institucionalmente. Há aqui uma justificativa para que a filosofia enquanto hermenêutica reflita sobre outras hermenêuticas áreas do conhecimento.

Segundo, considerando as definições apresentadas de hermenêutica, se neste primeiro estágio, Ricoeur já identifica a hermenêutica como um método preciso, ele ainda não se questiona sobre a própria natureza do compreender, outra definição que também envolve o termo hermenêutica. Desta forma, há aqui uma definição delimitada, de um instrumento que parece promissor para a investigação filosófica, perante o perigo do niilismo. Assim, o próprio filósofo francês comenta sobre este estágio da hermenêutica em sua obra:

[...] nesse primeiro estágio de minha investigação, a hermenêutica recebeu uma definição limitativa que mais tarde eu iria expandir: existe hermenêutica, ou seja, interpretação, lá onde existem expressões com duplo sentido, quando um sentido segundo tiver que ser desenvolvido a partir de um sentido primeiro. Certamente, essa definição era limitativa, mas dava ensejo a um desenvolvimento ulterior, inspirado na frase com a qual eu concluía A simbólica do mal: "O simbólico faz pensar" ("Le symboledonne à penser") (RICOEUR, 2011, p. 20). 
Em Da interpretação. Ensaio sobre Freud, Paul Ricoeur se vê diante de uma problemática diferente da apresentada em $A$ Simbólica do Mal, colocada por seu próprio tempo, a saber, problemática da linguagem.

\begin{abstract}
Parece-me que há um domínio sobre o qual se entrelaçam, hoje em dia, todas as pesquisas filosóficas: o da linguagem. É aí que se cruzam as investigações de Wittgenstein, a filosofia linguística dos ingleses, a fenomenologia oriunda de Husserl, as pesquisas de Heidegger, os trabalhos da escola bultmanniana e das outras escolas de exegese neotestamentária, os trabalhos de história comparada das religiões e de antropologia versando sobre o mito, o rito e a crença, enfim, a psicanálise (RICOEUR, 2011, p. 15).
\end{abstract}

Assim, com esta passagem, pode-se verificar a entrada de nosso autor na época do linguisticturn, ou como Manfredo Araújo de Oliveira prefere chamar, reviravolta linguísticopragmática na filosofia contemporânea. Oliveira descreve esta época da seguinte maneira:

\begin{abstract}
A linguagem se tornou, em nosso século, a questão central da filosofia. O estímulo para sua consideração surgiu a partir de diferentes problemáticas: na teoria do conhecimento, a crítica transcendental da razão, foi por sua vez, submetida a uma crítica e se transformou em "crítica do sentido" enquanto crítica da linguagem; a lógica se confrontou com o problema das linguagens artificiais e com a análise das linguagens naturais; a antropologia vai considerar a linguagem um produto especifico do ser humano e tematiza a correlação entre forma da linguagem e visão do mundo; a ética, questionada em sua racionalidade, vai partir da distinção fundamental entre sentenças declarativas e sentenças normativas. Com razão, se pode afirmar, com K. O. Apel, que a linguagem se transformou em interesse comum de todas as escolas e disciplinas filosóficas da atualidade (OLIVEIRA, 2006, p. 11).
\end{abstract}

Assim, a linguagem se torna central para a filosofia através de diversas problemáticas para seus autores. Neste sentido, segundo David Pellauer, Paul Ricoeur se insere na época da reviravolta linguística à sua própria maneira. Segundo Pellaeur, esta maneira própria está mais relacionada aos estudos linguísticos de sua época, do que à influência dos filósofos de tradição analítica (PELLAUER, 2014, p. 117).

Neste sentido, é através da problemática da linguagem que nosso autor analisa os escritos freudianos. Mas, por que Freud? A escolha de tal autor se dá por dois motivos principais: (i) através de sua análise dos sonhos, Freud convida seu leitor para uma interpretação em que se articula linguagem e desejo (RICOEUR, 1977, p. 17); no entanto, (ii) a interpretação simbólica freudiana é redutora, isto é, a psicanálise vê o símbolo como distorção da realidade, diferentemente da visão fenomenológica, como a apresentada em $A$ simbólica do mal, em que “[...] o símbolo é a manifestação de outra coisa que aflora no sensível: a expressão de um fundo que, podemos dizer, também se mostra e se oculta (RICOEUR, 1977, p. 18).

O reconhecimento, por parte de Ricoeur, da filosofia da linguagem pressuposta por Freud acaba sendo uma crítica à própria filosofia da linguagem pressuposta em $A$ Simbólica do Mal. O uso da hermenêutica pelo filósofo francês deixa de ser apenas um método preciso e passa a ser também uma reflexão sobre a própria natureza do próprio compreender e as condições de seu funcionamento. A nova definição de hermenêutica é a seguinte: "Por hermenêutica entenderemos sempre a teoria das regras que presidem a uma exegese, isto é, a interpretação de um texto singular ou de um conjunto de signos suscetível de ser considerado um texto" (RICOEUR, 1977, p. 19, grifo nosso). Esta definição já apresenta os elementos que também estão presentes em $A$ Crítica e $a$ 
Convicção, que é interpretação, método e reflexão, que é a definição que buscamos esclarecer no presente artigo.

Ora, se a primeira definição de hermenêutica, presente em $A$ simbólica do mal envolvia as definições em que hermenêutica é vista apenas como uma interpretação, a definição apresentada em Da interpretação. Ensaio sobre Freud mostra uma preocupação com uma hermenêutica que também seja epistemológica. Assim, Ricoeur declara: “O que me importa, na presente obra, não é a fecundidade de uma simbólica particular, mas a textura do símbolo que aí se revela. Em outras palavras, o desafio não consiste aqui no problema do mal, mas na epistemologia do símbolo" (RICOEUR, 1977, p. 23).

Em $O$ conflito das interpretações: ensaios sobre hermenêutica, Ricoeur procura descrever origem histórica do problema hermenêutico:

Não é inútil lembrar que o problema hermenêutico foi colocado, em primeiro lugar, nos
limites da exegese, vale dizer, no contexto de uma disciplina que se propõe a
compreender um texto, a compreendê-lo a partir de sua intenção, baseando-se no
fundamento daquilo que ele pretende dizer, um problema de interpretação, é porque
toda leitura do texto, por mais ligada que ela esteja ao quid, ao "aquilo em vista de que"
ele foi escrito, sempre é feita no interior de uma comunidade, de uma tradição ou de uma
corrente de pensamento vivo, que desenvolvem pressupostos e exigências; assim, a
leitura dos mitos gregos, na escola estóica, baseada numa física e numa ética filosóficas,
implica uma hermenêutica bastante diferente da interpretação rabínica da Torá na
Halancha ou na Haggada; por sua vez, a interpretação do Antigo Testamento, à luz do
evento cristico, pela geração apostólica, fornece uma leitura totalmente distinta dos
acontecimentos, das instituições, dos personagens da Bíblia, da leitura dos rabinos
(RICOEUR, 1978, p. 7).

Para além de sua origem cristã, em Da interpretação. Ensaio sobre Freud, outra tradição é citada por Ricoeur, que também é gérmen do problema hermenêutico, a tradição grega. De fato, o primeiro sentido de hermenêutica apresentado pelo dicionário Aurélio, como interpretação do sentido, é semelhante com a definição presente em Aristóteles quando ele afirma: hermenêutica “[...] é a significação da frase" (RICOEUR, 1977, p. 29). Neste sentido, hermenêutica só é interessante para Aristóteles, no sentido de que ela é o lugar do verdadeiro e do falso, ou melhor, do ser enquanto verdadeiro e falso. Com isso, o que a raiz grega revela é a pluralidade de sentidos que a hermenêutica deve promover:

Não digo que Aristóteles colocou o problema das significações multívocas tal como elaboramos aqui. Digo que apenas sua definição da interpretação como "dizer algo de alguma coisa" introduz a uma semântica distinta da lógica, e que sua discussão das múltiplas significações do ser abre uma brecha na teoria puramente lógica e ontológica da univocidade (RICOEUR, 1977, p. 30).

Porém, na tradição cristã, a definição de hermenêutica se apresenta como método, isto é, “[...] a hermenêutica é a ciência das regras da exegese, sendo entendida como interpretação particular de um texto" (RICOEUR, 1977, p.30). De certo modo, desde a hermenêutica simbólica, Paul Ricoeur buscava conciliar este modo hermenêutico com o modo grego, em busca da superação da crise de nossa modernidade. No entanto, nesta nova fase, esta conciliação é feita de um modo ainda mais crítico. Para Ricoeur, Nietzsche não foi apenas um autor que analisou de maneira exemplar a crise de nossa modernidade, mas "[...] nele [Nietzsche] é a própria vida que é interpretação: a filosofia torna-se, assim, interpretação das interpretações" (RICOEUR, 1978, p. 14). Em outra passagem, o filósofo francês afirma "[...] é toda filosofia que, com ele [Nietzsche], se torna interpretação" (RICOEUR, 1977, p.31). Se, em A simbólica do 
mal, Ricoeur apontava uma hermenêutica como superação do niilismo proclamado por Nietzsche, como reconhecimento de nossas raízes, em Da interpretação. Ensaio sobre Freud e $O$ conflito das interpretações: ensaios sobre hermenêutica, a hermenêutica apontada deve ser um método, como o cristão, porém crítico, ou seja, não deve cair na ilusão dos ídolos, como denuncia Nietzsche. Há aqui uma dupla preocupação:

[...] de um lado, purificar o discurso de suas excrescências, liquidar os ídolos, ir de embriaguez à sobriedade, elaborar um balanço da nossa pobreza; do outro, fazer uso do movimento mais "niilista", mais destruidor, mais iconoclasta, para deixar falar aquilo que uma vez, aquilo que cada vez foi dito quando o sentido reapareceu, quando o sentido era pleno. A hermenêutica me parece movida por essa dupla motivação: vontade de suspeita e vontade de ouvir - desejo de rigor, desejo de obediência. Somos hoje esses homens que não terminaram de matar os ídolos e que mal começaram a entender os símbolos. Talvez essa situação, em sua aparente desolação, seja instrutiva; talvez o iconoclasmo extremo pertença à restauração do sentido (RICOEUR, 1977, p. 33).

Deste modo, Ricoeur aponta o niilismo não como uma visão rival a sua hermenêutica, mas como um caminho que pode "purificar" sua empreitada. Se, segundo Ricoeur, a mesma modernidade que é responsável por nossa crise é aquela que oferece os instrumentos para superação da própria crise, não poderia o niilismo ser visto da mesma maneira? Ou seja, se o niilismo é uma postura perante a crise, ele não poderia ser considerado um instrumento de superação da própria crise? Para que esta alternativa seja possível, a própria noção de crise é ampliada.

Até o presente momento, a noção de crise foi entendida apenas como esquecimento de nossas raízes culturais e, por consequência, do ser humano como sagrado. Porém, agora, em vez de falar de uma crise, Paul Ricoeur fala de três crises: "[i] crise da linguagem, [ii] crise da interpretação e [iii] crise da reflexão - [que] só podem ser superadas conjuntamente" (RICOEUR, 1977, p. 55). A [i] crise da linguagem seria aquela postulada pelos lógicos, em que a linguagem natural é transformada pela univocidade da linguagem artificial, eliminando a pluralidade da linguagem simbólica. A [ii] crise da interpretação seria a falta de consideração das interpretações possíveis e, até mesmo, concorrentes. A [iii] crise reflexiva, a mesma já identificada em $A$ simbólica do mal, que é o esquecimento de nossas raízes, que pode nos levar ao niilismo. Sendo assim, podemos ver uma visão ontológica subjacente, a mesma identificada por Ricoeur em Aristóteles, e mais ainda, um alvo muito claro para sua hermenêutica, que deve envolver as possíveis interpretações, o reflexivo. Assim o próprio Ricoeur afirma:

Toda interpretação se propõe a vencer um afastamento, uma distância, entre a época cultural revoluta, à qual pertence o texto, o exegeta pode apropriar-se do sentido: de estranho, pretende torná-lo próprio; quer dizer, fazê-lo seu. Portanto, o que ele persegue através da compreensão do outro, é a ampliação da própria compreensão de si mesmo. Assim, toda hermenêutica é, explícita ou implicitamente, compreensão de si mesmo mediante a compreensão do outro (RICOEUR, 1978, p. 18).

É este o momento que Paul Ricoeur conquista uma hermenêutica que pode ser considerada como um conceito que melhor resume seu pensamento filosófico, uma vez que ele envolve tanto interpretação, como método, quanto reflexão. Neste sentido, hermenêutica é lugar em que o leitor encontra consigo mesmo por meio de uma leitura que ele faz da interpretação do outro. Em Interpretação Bíblica, o filósofo francês dirá que hermenêutica "[...] decifração da vida no espelho do texto" (RICOEUR, 2004, p. 49, grifo nosso), um outro jeito de falar de um conceito que já se fazia presente em Da interpretação: ensaio sobre Freud e em $O$ conflito das interpretações: ensaios de hermenêutica. 
Sendo assim, o ponto que cabe este artigo revelar é o seguinte: embora Ricoeur apresente sua hermenêutica envolvida em outras problemáticas e contextos, tal conceito permanece, a partir destas obras, sempre possuidora de três elementos, ou significações, que são interpretação, método e reflexão. A presença deste último elemento, da reflexão, é que aponta originalidade filosófica ricoeuriana e distinção perante outros grandes autores, como Gadamer, e garante sua grande aposta, que a melhor maneira de se conhecer é através de algo que é método que possibilita encontrar um si por meio da interpretação de um outro. Ou seja, entre outras coisas, hermenêutica para Paul Ricoeur é o lugar da investigação do si-mesmo como outro, que deu título a sua grande obra publicada em 1990, mas que, como mostramos, já estava presente em seus escritos dos anos 60, como Da interpretação: ensaio sobre Freud e $O$ conflito das interpretações: ensaios de hermenêutica. 


\section{Referências}

FERREIRA, Aurélio Buarque de Holanda. Dicionário Aurélio da língua portuguesa. Curitiba: Positivo, 2010. 2222 p.

GADAMER, Hans-Georg. Verdade e método: traços fundamentais de uma hermenêutica filosófica. Trad. Flávio Paulo Meurer. Petrópolis: Vozes, 1997. 731 p.

GRONDIN, Jean. Paul Ricoeur. Trad. Sybil Safdie Douek. São Paulo: Loyola, 2015. 121 p. (Coleção leituras filosóficas).

HOUAISS, Antônio; VILLAR, Mauro de Salles; FRANCO, Francisco Manoel de Mello. Dicionário Houaiss da língua portuguesa. Rio de Janeiro: Objetiva, 2004. 2922 p.

LAUXEN, R. R. Interfaces e distanciamentos entre a hermenêutica de Hans-Georg Gadamer e Paul Ricoeur. Revista Philósophos, v. 7, p. 127-158, 2012. Disponível em:

$<<$ https://revistas.ufg.br/philosophos/article/view/13942>>. Acesso em: 11 de out. 2019.

OLIVEIRA, Manfredo Araújo de. Reviravolta linguístico-pragmática na filosofia contemporânea. 3. ed. São Paulo: Loyola, 2006. 427 p.

PELLAUER, David. Ricœur's Own Linguistic Turn. Ricœur Studies, v. 5, n. 1, p. 115-124, 2014. Disponívelem: <<https://ricoeur.pitt.edu/ojs/index.php/ricoeur/article/view/217>>. Acesso em: 11 de out. 2019.

RICOEUR, Paul. História e verdade. Trad. F. A. Ribeiro. Rio de Janeiro: Forense, 1968. 340p. RICOEUR, Paul. Entrevista com Paul Ricoeur [sobre a crise da filosofia]. La philosophie d'aujourd'hui, Lausanne-Barcelone. Éditions Grammont-Salvat Editores (Bibliothèque Laffont des grandes thèmes), 1976. Trad. Universidade de Coimbra. Disponível em:

$<<$ http://www.uc.pt/fluc/uidief/textos_ricoeur/filosofia_actual >>. Acesso em: 11 de out. 2019. RICOEUR, Paul. Da interpretação: ensaio sobre Freud. Trad. Hilton Japiassu. Rio de Janeiro: Imago, 1977. 442 p. (Logoteca).

RICOEUR, Paul. O conflito das interpretações: ensaios de hermenêutica. Trad. Hilton Japiassu. Rio de Janeiro: Imago, 1978. 419 p. (Logoteca).

RICOEUR, Paul. A crise da consciência histórica e a Europa. Lua Nova: Revista de Cultura e Política, São Paulo, n.33, p.87-95, maio 1994. Disponível em:

$<<$ http://www.scielo.br/scielo.php?script $=$ sci_arttext\&pid=S0102-

$64451994000200007>>$.Acesso em: 11 de out. 2019.

RICOEUR, Paul. A crítica e a convicção. Trad. António Hall. Lisboa: Edições 70, 1995. 254 p. (Biblioteca de filosofia contemporânea).

RICOEUR, Paul. Interpretação bíblica. Trad. José Carlos Bento. São Paulo: Templus, 2004. 184 p.

RICOEUR, Paul Percurso do reconhecimento. Trad. Nicolás Nyimi Campanário. São Paulo: Loyola, 2006. 279 p.

RICOEUR, Paul. A memória, a história, o esquecimento. Trad. Alain François [et al.]. Campinas: Editora da Unicamp, 2007. $535 \mathrm{p}$

RICOEUR, Paul. Escritos e conferências 2 - hermenêutica. Trad. Lúcia Pereira de Souza. São Paulo: Loyola, 2011. 225 p. (humanística)

RICOEUR, Paul. Vivo até a morte. Trad. Eduardo Brandão. São Paulo: WMF Martins Fontes, $2012.97 \mathrm{p}$.

RICOEUR, Paul. A Simbólica do mal. Trad. Hugo Barros e Gonçalo Marcelo. Lisboa: Edições 70, 2017. $383 \mathrm{p}$.

Autor(a) para correspondência: Thiago Luiz de Sousa, Av. Antônio Carlos 6627 - Pampulha 31270901, Belo Horizonte-MG, Brasil. thiago-luiz-sousa@hotmail.com 